\title{
Las luchas del movimiento estudiantil rosarino del Cordobazo a la "primavera camporista" (1969-1973)
}

\author{
Mariano Millán \\ UBA - Conicet \\ marianomillan82@gmail.com
}

En este artículo analizamos la experiencia del movimiento estudiantil de Rosario entre el Cordobazo y la conclusión de la dictadura militar durante mayo de 1973, un contexto espacio-temporal relevante para la politica nacional del periodo, donde la izquierda y el movimiento obrero protagonizaron importantes hechos de masas.

Reconocemos cuatro variables complejas para la explicación de la experiencia estudiantil. La influencia de la coyuntura histórico-concreta; la acumulación histórica del movimiento; las ideologías estudiantiles y, finalmente, las luchas estudiantiles, ordenando los enfrentamientos en los cuales participaron los alumnos en cuanto tales de acuerdo a los objetivos, formas de acción, de organización, los aliados y los enemigos. ${ }^{1}$

Nuestra periodización de esta trayectoria, establecida a partir del desarrollo de la izquierda estudiantil y las relaciones entre movimiento estudiantil y movimiento obrero, produce datos que cuestionan ciertas hipótesis de uso común, hoy añejas: la crisis de la tradición reformista inaugurada en 1918 (Sigal, 1991: 71), la peronización de los estudiantes (Barletta, 2001: 83) y la escasa importancia de los reclamos propiamente universitarios (Sarlo, 2001). Compartimos la necesidad de explicar procesos de movilización que excedieron las aulas universitarias. Sin embargo, aquellas búsquedas acotadas a Buenos Aires y La Plata no analizaron los movimientos radicalizados de Córdoba, Rosario o Tucumán y, al mismo tiempo, tomaron como dimensión fundamental (casi

1. Trabajamos con cuatro tipos de fuentes: a) diarios La Capital y La Tribuna, de Rosario, y La Opinión, de Buenos Aires; b) una base de datos (en adelante, BDB) de probada fiabilidad y validez, con más de 20.000 registros de prensa sobre el movimiento estudiantil argentino entre 1966 y 1976 (ver Pablo Bonavena, 1990-1992); c) tres entrevistas en profundidad, y d) publicaciones militantes varias, que serán referidas al pie. Para la crónica de los enfrentamientos fueron consideradas a) y b).

(Archivos, año V, $\mathrm{n}^{\circ} 10$, marzo de 2017, pp. 141-161) 
única) el discurso de los estudiantes afines al peronismo, dejando en las sombras la experiencia de la izquierda reformista.

Si analizamos las luchas estudiantiles, identificamos a los grupos de izquierda (en un sentido amplio) que reivindicaban la herencia de la Reforma (el Movimiento Nacional Reformista [MNR], afin al Partido Socialista Popular [PSP]; el Movimiento de Orientación Reformista [MOR], enrolado en el Partido Comunista [PC]; y Franja Morada) como actores centrales del proceso de lucha y radicalización rosarino posterior al Cordobazo. La Federación Universitaria Argentina (FUA) y los centros de estudiantes resultaron organizativamente mucho más estables que los agrupamientos y articulaciones socialcristianas y/o peronistas, al tiempo que mostraron capacidad para la acción directa, la lucha de calles y para entablar alianzas con la clase obrera.

Asimismo, este trabajo cuestiona las problemáticas y extendidas tesis de Juan Carlos Portantiero, quien sostenia que las movilizaciones estudiantiles se debian a las dificultades del capitalismo latinoamericano para brindar una vía de ascenso social a la creciente masa de alumnos universitarios (1978: 14/5). En primer lugar, porque "el pleno empleo aún no vuelve verdaderamente perceptible la devaluación de los títulos escolares" (Sommier, 2009: 40). En segundo lugar, porque resultarian inexplicables las luchas por el ingreso a la universidad, importantes en el caso rosarino. Finalmente, porque esta concepción no permite observar las características específicas del fenómeno en cada situación política particular. Como veremos, el movimiento estudiantil rosarino experimentó mutaciones frente a las diferentes tácticas desplegadas por los gobiernos y autoridades universitarias del período.

\section{La acumulación del movimiento estudiantil rosarino}

Hacia mediados de los 60, la militancia estudiantil rosarina constituía un caso paradigmático de la hegemonía del reformismo universitario (Millán, 2013: 61). Los agrupamientos más importantes eran aquellos que, de diferentes maneras, reivindicaban la autonomía, el cogobierno, la educación laica y la formación de centros y federaciones estudiantiles. En este amplio espacio ubicamos al MNR, muy fuerte en Medicina; Franja Morada, hasta 1971 constituida por radicales, anarquistas y socialistas; y el citado MOR.

Más cercanos o lejanos a estas tradiciones, militaban el Frente de Agrupaciones Universitarias de Izquierda (FAUDI) de orientación maoísta [desde 1967], que respondia al Partido Comunista Revolucionario (PCR); la igualmente maoista TUPAC, que era la Tendencia Universitaria Popular Antiimperialista Combativa, ligada a Vanguardia Comunista; y la 
Tendencia de Agrupaciones Revolucionarias Estudiantiles de Avanzada (TAREA), que seguía la línea del PRT-La Verdad.

Frente al reformismo existían grupos socialcristianos y/o peronistas. El más importante era el Frente Estudiantil Nacional (FEN), mayormente constituido por activistas que se acercaron al peronismo desde la izquierda (Reta, 2010: 7) y luego se ubicaron en la ortodoxia. También existian colectivos más pequeños, autodenominados Movimiento de la Juventud Peronista (MJP). Como expresan numerosos documentos de la época, los justicialistas consideraban la universidad como una "isla democrática". La autonomía y el cogobierno no representaban cuestiones prioritarias y su actividad se enfocaba en reclutar militantes para otros frentes. En palabras de Luis César Bou: "Por aquellos años no nos interesábamos mucho en la dinámica interna de la universidad, éramos peronistas que veníamos a estudiar a la facultad y militábamos en el barrio". ${ }^{2}$

La predominancia de la identidad reformista entre los alumnos explica su tenaz resistencia frente al golpe de Estado de 1966 y la intervención universitaria. Sin embargo, la oposición estudiantil se encontraba aislada en un contexto signado por los múltiples apoyos sociales a la dictadura. El rector y los decanos renunciaron y los alumnos se movilizaron contra las autoridades nacionales. No obstante, fueron derrotados. En Rosario durante 1967, como en casi todo el país, primó una relativa pacificación social. El éxito del programa económico de Krieger Vasena y la derrota del sindicalismo en marzo configuraron un escenario adverso para la movilización social.

Diferente fue 1968, cuando comenzó un período de recomposición del movimiento estudiantil. Inició con reclamos corporativos y, meses después, los alumnos ganaron las calles para enfrentar al gobierno: reclamaban el retorno a la universidad reformista y recordaban a Santiago Pampillón, asesinado en 1966 y, desde entonces, un mártir. Sobre estos ejes se desarrollaron alianzas con sectores profesionales y fracciones obreras como la CGT de los Argentinos (CGT-A), al tiempo que la lucha callejera se convirtió en la forma de acción predominante. Mencionaremos los dos acontecimientos más salientes de esta confluencia. El primero fue la alianza obrero-estudiantil (que incluyó a los empleados judiciales) en la vía pública durante la conmemoración del 50 aniversario de la Reforma de 1918 (González et al., 2009: 31-38), cuando el paro de la FUA logró suspender las clases, a pesar del boicot de las agrupaciones peronistas. El segundo, durante la primera huelga de la CGT-A en el invierno de 1968. La izquierda reformista rosarina y la FUA a nivel nacional participaron activamente de la organización de

2. Entrevista a Luis César Bou, militante estudiantil del MJP, estudiante de Filosofia y Letras. Realizada por el autor durante noviembre de 2009. 
actos junto a la central sindical (Bonavena y Millán, 2007). En ambos casos, la organización obrera facilitó locales, emitió comunicados de solidaridad con el movimiento estudiantil e integró a la izquierda reformista en los actos, junto a los dirigentes sindicales. En contrapartida, la articulación en 1968 de la Unión Nacional de Estudiantes (UNE), donde eventualmente se nuclearon socialcristianos y peronistas, poco cambió el panorama nacional incluso para los justicialistas, que la consideraron "una opción" sin capacidad para dirigir al movimiento estudiantil. ${ }^{3}$

Hacia mayo de 1969, la crisis nacional desencadenada con el asesinato del alumno Juan José Cabral en Corrientes tuvo uno de sus epicentros en Rosario. Las acciones enmarcadas en el plan de lucha de la FUA recibieron duras respuestas represivas. El día 17 fue abatido Adolfo Ramón Bello, en lo que fue sentido como un verdadero hecho brutal por amplias capas de la población rosarina. Ambas CGT y numerosos gremios se manifestaron en solidaridad y la ciudad se convirtió en el escenario de importantes movilizaciones y luchas callejeras hasta la Marcha del Silencio del 21, cuando tuvo lugar uno de los hechos de masas más importantes del periodo. Durante aquella jornada, estudiantes, obreros y pobres de la ciudad tomaron control del centro y la policía se acuarteló tras haber asesinado al joven Norberto Blanco.

Siguiendo los planteos de Bou (2002) y Pérez y Viano (1994), el mayo rosarino estuvo articulado centralmente alrededor de la revuelta estudiantil y la huelga nacional de la FUA, que consiguió el apoyo de los trabajadores de la ciudad y de otras fracciones subalternas. Distinto fue el caso del Cordobazo durante los días posteriores, una revuelta urbana bajo la conducción obrera (Millán, 2013: 161).

Más allá de estas diferencias, el ciclo de mayo de 1969 motivó importantes debates en el seno del movimiento estudiantil y la izquierda. La izquierda reformista moderada, el MNR y algunos grupos de Franja Morada, propugnaban la consigna "Elecciones libres, sin condicionamientos ni proscripciones". Otros grupos de la Franja, afines al anarquismo, y el FAUDI se alineaban con la consigna "Ni golpe ni elección, revolución". Como demostró Celentano (2014), estos acontecimientos catalizaron un proceso de organización del maoísmo. A su vez, algunas variantes de izquierda, como el PRT El Combatiente, vieron en los hechos de mayo de 1969 el "inicio de una "guerra civil"" (Mangiantini, 2014: 117) y la necesidad de constituir una organización político-militar. Sin embargo, sería excesivo considerar algunas de estas diferencias como irreconciliables. A fines de 1970 se dividió la FUA. Los insurreccionalistas de FAUDI se aliaron con los demo-burgueses del MNR y Franja Morada y enfrentaron al prosoviético MOR (que no cesó en sus intentos

3. “UNE ¿tendencia u opción?”, Patria Grande, octubre de 1968, n² 2, p. 11-12. 
de conquistar a los segundos), formándose la "FUA Córdoba" y la "FUA La Plata" respectivamente (Millán, 2013: 178).

\section{Del Cordobazo al GAN}

Después del Cordobazo el gobierno de Onganía buscó descomprimir la situación política. El nuevo gabinete de ministros procuró una "mayor "sensibilidad social"" (O’Donnell, 2009: 246). En Cultura y Educación Pérez Gillhou se propuso aplicar la legislación de 1967, que establecía la elección del gobierno universitario por parte de Consejos Académicos compuestos de representantes de los profesores, y cursos y/o exámenes de ingreso, con la intención de restringir el volumen del alumnado que se había incrementado en un 65\% entre 1961 y 1969 (Pérez Lindo, 1986: 131). Menguó la política reactiva y difusa contra el movimiento estudiantil y se esbozaron intentos "dialoguistas" para contener la movilización, motivando serias disputas en el gobierno (Califa y Millán, 2016: 16).

En Rosario, la situación política inicial estuvo signada por el Rosariazo de septiembre. Aunque en esta ciudad no se formaron los Consejos Académicos hasta 1973, la aplicación de exámenes de ingreso motivó una importante resistencia estudiantil.

La segunda parte de 1969: la conducción obrera de la alianza obrero-estudiantil

Tras el Cordobazo regresaron las acciones combativas de los alumnos, tanto para repudiar la represión, como para reivindicar el mayo rosarino y los mártires estudiantiles. Hubo actividades por el aniversario de la Reforma y seorganizaron comités de enlace con organizaciones obreras. Frente a la llegada de Nelson Rockefeller al país durante junio, el movimiento estudiantil rosarino y argentino, tanto la izquierda reformista (FUA, MNR y MOR) como el FEN, desarrolló una breve pero intensa campaña de agitación callejera y ataques a ciertos símbolos del poder norteamericano (agencias de autos, el servicio informativo de los Estados Unidos, etc.) y de la oligarquía local (el Jockey Club, el diario La Capital).

A su vez, en confluencia con la CGT, los estudiantes participaron de las acciones en repudio a la visita de Onganía a la ciudad, el 20 de junio. Hicieron lo propio luego, durante las huelgas de la central obrera el 1 de julio y el 27 de agosto, desarrollando actos relámpago, erigiendo barricadas y un breve mitin conjunto (con oradores del Partido Comunista) en la segunda de aquellas fechas.

Mientras se aproximaba un nuevo aniversario del asesinato de Santiago Pampillón, desde la segunda semana de septiembre los estudiantes organizaron actividades en su memoria que permitieron confluir a sus 
agrupaciones, más allá de sus diferencias programáticas. Se realizaron asambleas en todas las facultades, una huelga estudiantil de la FUA, varias ocupaciones de edificios y numerosas manifestaciones que derivaron en lucha de calles con barricadas y protestas relámpago. Algunos actos fortalecieron los vínculos con la clase obrera, como el del Centro de Estudiantes de Medicina conducido por el MNR, donde participó el Secretario de la CGT local Héctor Quagliano. ${ }^{4}$ Este ciclo de movilización empalmó con el paro del 16 y 17 de septiembre, que concluyó en el Rosariazo.

Durante los días previos todo el movimiento estudiantil se convirtió en un soporte de la huelga obrera de Rosario y en contra de la dictadura militar. La respuesta a la sanción para los empleados del ferrocarril que se habian solidarizado con los alumnos durante mayo desató un conflicto que concluyó en otro hecho de masas. Estudiantes de la izquierda reformista (FUA, MOR, MNR y FAUDI) y del peronismo como la Unión de Estudiantes del Litoral (UEL) invitaron a concurrir a las marchas y concentraciones. Desde el 16 se cumplió con gran acatamiento el paro de 36 hs. de la CGT de Rosario. Los trabajadores abandonaron los establecimientos constituyendo una marcha de unas 30.000 personas, de las cuales cerca de 4.000 eran estudiantes (Balvé y Balvé, 2005: 191).

El movimiento estudiantil se encuadró, organizadamente, como una fuerza auxiliar en la alianza obrero-estudiantil durante el Rosariazo. Más allá de las diferencias entre agrupaciones, los alumnos brindaron su apoyo de modo unificado según la facultad donde cursaban. Declararon un paro de 48 horas pero no se concentraron en las casas de estudios, sino que se incorporaron a las columnas proletarias en distintos lugares de la ciudad (Pérez y Viano, 1994: 107), "no se organizan en columnas separadas de los obreros ni deciden identificarse en tanto esta personificación" (Balvé y Balvé, 2005: 197). Aldo Mangiaterra refiere: "Nosotros sabíamos con antelación adónde y en qué momento nos teníamos que sumar a las columnas obreras. Cada Facultad tenía su lugar en la ciudad que determinaba sus acciones de apoyo a la movilización de los trabajadores". ${ }^{5}$ En este sentido, los activistas de Medicina se incorporaron a la formación de operarios y empleados de Minetti y los de Ingeniería a la marcha de los portuarios hacia el centro.

Hacia el mediodía todas las fracciones obreras se hallaban en huelga y Rosario estaba llena de sólidas barricadas. Los obreros y estudiantes se reagrupaban frente a los ataques policiales, iniciando una ofensiva en el centro de la ciudad que logró controlar el casco urbano por la

4. "Está en marcha la revolución del pueblo", CGT, septiembre de 1969, n 51, p. 4. 5. Aldo Mangiaterra, militante estudiantil de Ingeniería, dirigente del MOR y luego de FAUDI. Entrevista realizada por el autor en noviembre de 2009. 
tarde y durante 36 horas. Los alumnos aportaron su experiencia en la lucha de calles, su organización y sus vidas. Uno de los dos muertos del Rosariazo fue el estudiante Juan Carlos Sánchez, de 18 años. La ciudad fue diezmada materialmente y las pérdidas alcanzaron cifras millonarias. Los incidentes fueron perdiendo intensidad durante los dias siguientes, hasta casi desaparecer.

Tras estos hechos el campo de alianzas del movimiento estudiantil en la ciudad se restringió predominantemente a la clase obrera. Las coincidencias entre fracciones de la pequeña burguesía y los alumnos fueron cada vez más frágiles y episódicas.

En este contexto se produjeron realineamientos dentro del movimiento estudiantil. Muchos de ellos reflejaban diferencias que en los momentos más álgidos del conflicto, como mayo o septiembre, eran subsumidas al proceso de movilización. En noviembre de 1969 la FUA, conducida por FAUDI, convocó a un congreso de unidad con un "programa de acción antiintervencionista, antidictatorial, antiimperialista y liberador". ${ }^{6}$ Varias organizaciones afines al peronismo como el Integralismo, FEN y la Unión Nacional de Estudiantes (UNE) erigieron una Coordinadora de la Línea Nacional (CALN), lo que cristalizaba su ruptura con la FUA y los centros de estudiantes: "La línea organizativa fue y es consecuencia [...] de la política. Bregamos en todos los casos por fortalecer el peso de la línea nacional criticando a la ultraizquierda y al reformismo [...] Donde los centros juegan ese papel, los impulsamos. Donde no, tratamos de superarlos". ${ }^{7} \mathrm{El} \mathrm{FEN}$, principal agrupamiento peronista en la universidad rosarina, desde 1970 comenzó un tránsito hacia la ortodoxia, aliándose con Guardia de Hierro y luego formando la Organización Única para el Trasvasamiento Generacional (OUTG). En ese proceso fueron relegando la militancia universitaria y centrándose en la actividad partidaria, con mayor anclaje barrial. Algunos analistas consideraron esta trayectoria como consecuencia del declive de la CGT-A (Ruiz y Vargas, 2013), aunque ciertos testimonios recuerdan la existencia de "algunos medio fascistas" en los espacios de sociabilidad peronistas de la segunda mitad de los 60, nucleados por el "rechazo al comunismo" (Neirot, 2010: 52), siguiendo la tradición de Tacuara (58).

De nuestra observación de las luchas estudiantiles rosarinas de 1969 se desprende el rol central del reformismo universitario, donde distintas variantes de izquierda (FUA, MNR, MOR, FAUDI) tenian un peso significativo. Los hechos de masas de este año coexistieron con el

6. "Hacia el congreso nacional de unidad. La crisis del movimiento estudiantil", Cristianismo y Revolución, enero de 1970, $\mathrm{n}^{\circ} 22$, p. 26.

7. "Declaraciones del FEN (Frente Estudiantil Nacional)", Cristianismo y Revolución, enero de $1970, \mathrm{n}^{\circ} 22$, p. 33. 
fortalecimiento de los centros de estudiantes, como en Medicina, donde APRI, del MNR, triunfó con 1.000 votos en una elección ilegal donde participó el $40 \%$ de los alumnos de la Facultad, ${ }^{8}$ o los intentos de esta misma agrupación del PSP por reconstruir el Centro de Estudiantes de Ciencias Económicas. Esta importante corriente del movimiento estudiantil, que presidió una de las FUA desde 1971, expresaba la tensión entre lo institucional y la acción directa, como cuando escrachó, con una movilización de cientos de alumnos, al Ministro de Educación en su visita a Rosario a fines de noviembre. Por estas acciones fueron sancionados tres alumnos, quienes serian defendidos con movilizaciones durante el primer semestre de 1970.

Con esto no afirmamos la inexistencia de los grupos peronistas, sino que cuestionamos su importancia en el proceso de organización y movilización estudiantil, y en la construcción de la alianza con el movimiento obrero. A pesar de contar con asientos en los edificios de la CGT-A (Califa, 2016: 147-148), una contabilidad de las acciones obreroestudiantiles de nuestro período en Rosario, discriminando según la fracción de alumnos, arroja un resultado contundente: los reformistas en soledad protagonizaron más de la mitad (ver cuadro $\mathrm{n}^{\circ} 1$ ).

Al mismo tiempo observamos que existe un declive notorio en la cantidad de las acciones. Mientras el segundo semestre de 1969 concentra 14, los años siguientes descienden hasta prácticamente desaparecer. Es importante señalar que la unificación de las dos tendencias de la CGT se produjo en Rosario durante mayo de 1969 y la dirigencia vandorista logró, tras varias maniobras, conquistar la dirección de la central obrera local. ${ }^{9}$ En este sentido, el sindicalismo rosarino fue de los primeros en unificarse desde la identidad peronista, una tendencia señalada por Pozzi y Schneider (2000: 61) para todo el país en los años subsiguientes. La historia de esta alianza obrero-estudiantil tiene sintonía con lo ocurrido en Buenos Aires, donde perdió tonicidad durante los primeros 70 (Califa, 2016: 151-155), una trayectoria muy diferente a la de Córdoba, con el Viborazo de 1971 y las luchas por el ingreso en 1970 y 1971; o Tucumán, con el Tucumanazo de 1970 y el Quintazo de 1972 (Millán, 2013). En Rosario, el movimiento estudiantil desarrolló numerosas luchas por demandas académico-corporativas y contra la represión durante los años siguientes.

8. "Triunfó el APRI en el Centro de Estudiantes de Ciencias Médicas", La Tribuna, 25 de octubre de 1969, p. 7. Resultados: APRI, 1.000; AREL (FEN), 138; PR, 134; en blanco, 78. Según la Información estadística de la UNR de 1980 (p. 12), en 1969 habia 3.369 alumnos inscriptos en la Facultad.

9. "Rosario en la encrucijada", CGT, noviembre de 1969, nº 53, pp. 3 y 8. 


\section{Cuadro $\mathrm{n}^{\circ} 1$}

Acciones obrero-estudiantiles en Rosario según fracción estudiantil (excluyendo el Rosariazo), desde el Cordobazo hasta el 25 de mayo de 1973

\begin{tabular}{|c|c|c|c|c|c|c|}
\hline Tipo de acción & 1969 & 1970 & 1971 & 1972 & 1973 & Total \\
\hline $\begin{array}{l}\text { Comunicado } \\
\text { Reformista } \\
\text { Peronista } \\
\text { Sin datos }\end{array}$ & $\begin{array}{l}4 \\
0 \\
1\end{array}$ & $\begin{array}{l}2 \\
1 \\
1\end{array}$ & $\begin{array}{l}2 \\
2 \\
0\end{array}$ & $\begin{array}{l}0 \\
0 \\
0\end{array}$ & $\begin{array}{l}4 \\
1 \\
0\end{array}$ & $\begin{array}{r}12 \\
4 \\
2\end{array}$ \\
\hline $\begin{array}{l}\text { Comité obrero- } \\
\text { estudiantil }\end{array}$ & 1 & 0 & 0 & 0 & 0 & 1 \\
\hline $\begin{array}{l}\text { Solidaridad } \\
\text { obrera }\end{array}$ & 2 & 0 & 1 & 0 & 0 & 3 \\
\hline $\begin{array}{l}\text { Acto en edificios } \\
\text { Reformista } \\
\text { Peronista } \\
\text { Sin datos }\end{array}$ & $\begin{array}{l}1 \\
1 \\
0\end{array}$ & $\begin{array}{l}1 \\
0 \\
0\end{array}$ & $\begin{array}{l}1 \\
0 \\
0\end{array}$ & $\begin{array}{l}0 \\
0 \\
0\end{array}$ & $\begin{array}{l}0 \\
0 \\
0\end{array}$ & $\begin{array}{l}3 \\
1 \\
0\end{array}$ \\
\hline $\begin{array}{c}\text { Acto en calle } \\
\text { Reformista } \\
\text { Peronista } \\
\text { Sin datos }\end{array}$ & $\begin{array}{l}1 \\
0 \\
3\end{array}$ & $\begin{array}{l}1 \\
0 \\
2\end{array}$ & $\begin{array}{l}2 \\
1 \\
0\end{array}$ & $\begin{array}{l}0 \\
0 \\
0\end{array}$ & $\begin{array}{l}0 \\
0 \\
0\end{array}$ & $\begin{array}{l}4 \\
1 \\
5\end{array}$ \\
\hline $\begin{array}{l}\text { Totales } \\
\text { Reformista } \\
\text { Peronista } \\
\text { Sin datos } \\
\text { Otros } \\
\text { Total }\end{array}$ & $\begin{array}{r}6 \\
1 \\
4 \\
3 \\
14\end{array}$ & $\begin{array}{l}4 \\
1 \\
3 \\
0 \\
8\end{array}$ & $\begin{array}{l}5 \\
3 \\
0 \\
1 \\
9\end{array}$ & $\begin{array}{l}0 \\
0 \\
0 \\
0 \\
0\end{array}$ & $\begin{array}{l}4 \\
1 \\
0 \\
0 \\
5\end{array}$ & $\begin{array}{r}19 \\
6 \\
7 \\
4 \\
36\end{array}$ \\
\hline
\end{tabular}

Fuentes: La Capital, La Tribuna y BDB.

1970: de las facultades a las calles, ida y vuelta

A principios de 1970 el gobierno de facto implementó exámenes de ingreso en las universidades nacionales. En respuesta, el movimiento estudiantil realizó actividades combativas en varios puntos del país. En Rosario los reclamos comenzaron durante febrero y tuvo lugar un amplio proceso de movilización. El 23 se inició la semana de lucha contra el sistema de ingreso. Las agrupaciones afiliadas a la CALN anunciaron medidas de lucha, al igual que el MOR, quien convocó a enfrentar la dictadura, el limitacionismo y consolidar la lucha en todos los claustros; $;^{10}$ diferenciándose de quienes no respaldaban las organizaciones reformistas. Ambas vertientes rechazaban los exámenes de admisión, pero con

10. "Convoca a los estudiantes universitarios el MOR de Rosario", Nuestra Palabra, 24 de marzo de 1970, p. 8. 
distintos métodos organizativos. En Rosario, a diferencia de Córdoba, la CGT no expresó su apoyo al reclamo estudiantil. ${ }^{11}$

Se realizaron varias y nutridas asambleas en el comedor universitario y distintas acciones de sabotaje, como piquetes y destrucción de hojas de exámenes. A mediados de marzo hubo importantes conquistas: los aspirantes de Ciencias Económicas, Arquitectura y Filosofia ingresaron en su totalidad. En esta Facultad el estudiantado había logrado que el curso no fuera limitativo y se modificase su contenido: doce charlas de una hora y media acerca de diálogo y participación, formas de lucha, la Universidad y el país, los estudiantes y el movimiento obrero y los programas de las materias. ${ }^{12}$ Los mayores éxitos organizativos parecen haber sido en la regional de la UTN, donde participaron cada uno de los 500 aspirantes, quienes formaron un cuerpo de delegados con permiso para reunirse y deliberar en los cursos y, además, consiguieron el ingreso irrestricto.

En abril, tras estas victorias, se reanudaron las protestas contra las sanciones de diciembre, donde subrayamos dos cuestiones: las autoridades universitarias se constituyeron como el blanco principal de los reclamos y reaparecieron las formas de lucha violentas. Estas confrontaciones tenian por escenario la universidad y la vía pública. Hubo paros y ocupaciones estudiantiles, con rehenes incluidos, en Arquitectura. El decano sancionó a 35 estudiantes, mantuvo clausurado el Centro de Estudiantes y el Ateneo durante varias semanas y ordenó el registro del acceso al edificio. En mayo estalló una bomba en su domicilio.

Para ese momento, ya se profundizaba la unidad del movimiento estudiantil rosarino. La UNE trazó un plan de lucha coincidente con el de FUA, en momentos en que ésta propugnaba un acercamiento a ese sector, a la CGT opositora y a los sacerdotes del Tercer Mundo.

Durante mayo las movilizaciones estudiantiles en reivindicación de los hechos de 1969 relocalizaron al poder politico de la dictadura como enemigo directo, lo que facilitó una nueva confluencia con la CGT y el movimiento obrero.

Desde el día 14 hubo luchas callejeras. El paro estudiantil del 15 y 16 tuvo alto acatamiento también en las escuelas secundarias y un impacto significativo sobre la ciudad, disminuyendo notoriamente la actividad corriente y presenciándose numerosos encuentros violentos en la vía pública. Ya para el 17 una nueva huelga activa secundaria y

11. "Se alzan los estudiantes cordobeses", Nuestra Palabra, 3 de febrero de 1970, p. 7; "Vacaciones combativas de los estudiantes cordobeses", La Verdad, 17 de febrero de 1970 , p. 7.

12. "Filosofia de Rosario. La intervención se "populiza", La Verdad, 30 de marzo de 1970, p. 8. 
universitaria tuvo observancia parcial y la ciudad fue cubierta por una fuerte vigilancia policial.

Pese a ello, el recuerdo de los mártires y de los hechos brutales de la dictadura continuaba siendo una herramienta que el movimiento estudiantil utilizaba para construir alianzas: el MOR realizó un acto de homenaje a Bello y Blanco en los tribunales de la provincia, donde uno de los oradores fue el ex juez Frávega; el Centro de Estudiantes de Medicina anunció otro para el día 20 y diversos grupos estudiantiles junto a la CGT Regional preparaban un tercero para el 21. Ninguno de ellos alteró las actividades normales.

El día 21 se llevó adelante, en el Cementerio La Piedad, un homenaje a Blanco que contó con 600 participantes, entre ellos familiares, miembros de la central obrera y de entidades estudiantiles. Luego, alrededor de 2.000 alumnos marcharon en silencio por el centro y recogieron aplausos de la población. Sin embargo, pronto chocaron con la policía y la zona se convirtió en el teatro de operaciones de una batalla urbana que, por primera vez durante esta etapa en Rosario, incluyó el uso de armas de fuego por ambos bandos. Durante la jornada siguiente una manifestación de 5.000 estudiantes, duramente reprimida, inició la "Semana de Conmemoración del Cordobazo". Para el día 29 también hubo luchas callejeras intensas, aunque la policía frustró las actividades más importantes en Plaza Sarmiento y Galería Melipal.

Con posterioridad a estos hechos, el movimiento estudiantil entró en un reflujo y se replegó hacia cuestiones académico-corporativas. Las autoridades universitarias volvieron a ubicarse como los enemigos directos y la forma predominante fue la acción directa, fundamentalmente la ocupación de los inmuebles universitarios. La más importante de estas confrontaciones se produjo en Medicina, donde la Coordinadora Estudiantil, que agrupaba a todas las fracciones, repudió al Decano y a su plan de estudios.

Durante julio, en consonancia con el golpe de Estado que colocó a Levingston en la Presidencia de la Nación, el movimiento estudiantil reformista de Rosario inició una ofensiva para destituir al rector Cantini, quien fue nombrado Ministro de Educación. En su lugar fue designado Sol Libertario Rabasa. La lucha estudiantil regresó para septiembre, con la conmemoración del aniversario de la caída de Pampillón y del Rosariazo. Los alumnos llamaron a una huelga, que concitó escasa adhesión, y las manifestaciones no lograron ocupar el centro de la ciudad, produciéndose varios choques con la policía que dejaron heridos de bala. Posteriormente, con epicentro en Medicina, hacia fines de noviembre los conflictos de los no docentes y de los obreros del frigorífico Swift despertaron la solidaridad estudiantil, especialmente del Centro de Estudiantes, que expresó su apoyo a los trabajadores. A pesar de 
estas tenues confluencias, las derrotas calaron profundo y el movimiento ingresó en un declive hasta el verano de 1971.

\section{La lucha por el ingreso irrestricto durante 1971}

El inicio de 1971 estuvo signado por las movilizaciones contra los exámenes de admisión. En Rosario la lucha estudiantil tuvo que enfrentar funcionarios particularmente resueltos, pues el Ministro de Educación, doctor Cantini, era el saliente Rector de la UNR y había dejado su equipo de colaboradores en la ciudad.

Los enfrentamientos se iniciaron en febrero con la toma de la Facultad de Ingeniería. Luego 500 estudiantes hicieron lo propio en Ciencias Económicas $\mathrm{y}$, días después, los alumnos de los cursos de ingreso ocuparon casi todas las Facultades de la UNR. Posteriormente varios centenares de estudiantes, convocados por la Coordinadora del Preuniversitario, se congregaron frente al rectorado solicitando una entrevista, situación en la cual fueron dispersados por la policía. Notamos que, al desenvolverse los conflictos, se desarrollaban mecanismos de unidad como las coordinadoras estudiantiles.

Al comenzar marzo, en todos los establecimientosse habían colocado parlantes para explicar a la ciudadanía los motivos de las tomas y numerosas comisiones de estudiantes recorrian las zonas aledañas parando automóviles y solicitando ayuda "para mantener la lucha". Por su parte, el MNR resolvió que no se rindiesen los exámenes hasta que no fuera solucionado el problema del preuniversitario y, al mando del Centro de Estudiantes de Medicina, aceptó un donativo de $\$ 50.000$ del Ejército Revolucionario del Pueblo (ERP).

Durante la madrugada del 5 de marzo, a pedido de los decanos y la justicia, policias federales y provinciales desalojaron las siete facultades de la UNR. Hubo incidentes en Filosofia y también en Ingenieria, donde los estudiantes rompieron sillas, mesas y bancos. En las otras facultades no hubo resistencia ni detenidos, sin embargo esa misma mañana los estudiantes reocuparon varios edificios y realizaron una marcha que concluyó con enfrentamientos. Recién en estas circunstancias la CGT rosarina expresó su apoyo hacia los estudiantes. Pese a ello, el movimiento contra los exámenes de admisión en Rosario se encontraba en franco retroceso, siendo derrotado durante los meses subsiguientes, caracterizados a nivel nacional por la crisis política tras el Viborazo y el golpe de Estado encabezado por Lanusse.

\section{El movimiento estudiantil bajo el GAN}

Una de las iniciativas presidenciales más tempranas de Lanusse 
consistió en el Gran Acuerdo Nacional (GAN), repliegue de los militares y apertura pactada con los partidos políticos tradicionales. La vida política del país se polarizó por la aceptación o rechazo del GAN y, luego, por las pujas entre quienes aceptaron la salida electoral de 1973. La legalización de la actividad política, entendida como mera compulsa institucional, permitió a la dictadura observar las diferencias entre quienes reclamaban desde un punto de vista democrático burgués y aquellos que desarrollaban la lucha revolucionaria, ensayando respuestas acordes (Bonavena et. al., 1998).

Entre las acciones del movimiento estudiantil rosarino del período identificamos dos ejes principales: los problemas académico-corporativos (planes de estudio, cátedras "filtro", impugnación político-ideológica a profesores) y la lucha antirrepresiva. El predominio del primero, observable en las fracciones sociales movilizadas y los escenarios en donde se desarrollaban las luchas, profundizó el relativo aislamiento estudiantil en el marco de la decreciente cantidad de enfrentamientos comunes con los aliados de la clase obrera (durante estos dos años casi no encontramos acciones con la CGT local) o de la pequeña burguesía. Algunas de estas fracciones sociales se enrolaron en la politica institucional y por ello acotaron, a instancias de ciertas direcciones políticas, sus prácticas de acción directa y lucha de calles. El segundo eje, la cuestión antirrepresiva, representó una reacción a la respuesta contrarrevolucionaria de las clases dominantes corporizada en la emergencia de prácticas represivas clandestinas, que se combinaron con medios legales, ordinarios y de excepción, contra el movimiento estudiantil desde 1971 (Califa y Millán, 2016).

\section{1: el año del conflicto en Medicina}

Durante 1971 el movimiento estudiantil rosarino llevó adelante procesos de movilización más acotados que los de años anteriores y de escasa relación con la clase obrera; centrados en reclamos antirrepresivos y cuestiones académico-corporativas, destacándose la contienda de Medicina, donde los conflictos se prolongaron por ocho meses.

A principios de abril, los alumnos de aquella Facultad señalaron al decano Manuel González del Cerro como responsable de la represión durante el verano. Ocuparon el edificio y decidieron no rendir exámenes. Las autoridades cerraron esa casa de estudios. La respuesta estudiantil fue redoblar la agitación: la toma duró más de 10 dias, hasta el 13 de abril, cuando la policía desalojó a los alumnos, quienes resistieron en las calles erigiendo barricadas.

Casi un mes después, a mediados de mayo, FUA, FEN y los Centros de Estudiantes intentaron desarrollar actos en memoria de Adolfo 
Ramón Bello y de los hechos de mayo de 1969. La policía impidió las manifestaciones céntricas y se produjeron choques con armas de fuego en algunos puntos de la ciudad.

En días posteriores comenzó un movimiento de protesta por las carencias edilicias en la Facultad de Arquitectura. Hubo asambleas y clases en las calles, además de numerosas volanteadas para informar a los habitantes de la ciudad. Tras dos semanas de movilización el decano aceptó el petitorio docente-estudiantil y, hacia fines de junio, comenzaron las clases de 1971.

Casi al mismo tiempo, en Ingeniería un grupo de más de 800 estudiantes realizó un juicio político a la Universidad. Hubo un rechazo unánime a la politica universitaria de "apertura" del ministro Malek y la Universidad fue condenada como una institución al servicio del imperialismo y los privilegiados del país, dirigida por quienes participaron de la represión y persecución del movimiento popular. El decano de la Facultad, Manuel Gorullón, decidió cerrar esta casa de estudios. Los alumnos se apostaron en las puertas y lograron la reapertura tras una semana.

Como subrayamos al describir las luchas por el ingreso y en Arquitectura, durante el período de la declinación de su alianza con la clase obrera el movimiento estudiantil desarrolló tácticas de interpelación pública para los habitantes de la ciudad en general, repartiendo volantes, emitiendo discursos por altavoces, etc. Advertimos, por ejemplo, que no llegó a constituirse una cooperación entre el movimiento estudiantil local y la experiencia clasista de la Comisión Intersindical de San Lorenzo (que ocurria al mismo tiempo a pocos kilómetros) de la misma densidad que la desarrollada durante mayo y septiembre de 1969 o la que podía observarse en Córdoba (Millán, 2013). Arriesgamos la hipótesis de una debilidad relativa de los grupos marxistas en la UNR y de la articulación obrera, surgida como "una organización defensiva y solidaria, producto de la situación del movimiento obrero regional y los importantes conflictos perdidos" (Ceruti y Resels, 2006: 152).

Casi un mes después del conflicto de Ingeniería, a principios de agosto, se conoció la noticia del secuestro de los militantes de las FAR Juan Pablo Maestre y Mirtha Misetich. ${ }^{13}$ Todas las ramas del movimiento estudiantil rosarino se manifestaron en las calles. En las siguientes semanas se produjeron varios hechos de violencia entre estudiantes y policías, tanto a partir de la ocupación del comedor, como en actos de solidaridad con el pueblo vietnamita promovidos por FAUDI y TUPAC.

Durante agosto y septiembre, los alumnos de Ciencias Políticas y

13. En pocos días apareció el cadáver del primero, la segunda permanece desaparecida. 
los de Psicología y Ciencias de la Educación cuestionaron los planes de estudios y a varios profesores de sus carreras mediantes distintas acciones de lucha. En el segundo caso la policía actuó sobre los manifestantes, produciéndose numerosos enfrentamientos.

Como todos los años de este período, el 12 de septiembre los estudiantes realizaron distintas actividades en recuerdo de Santiago Pampillón. En esta oportunidad grupos de UEL, UNE y FEN realizaron varios actos relámpago, atacando la fachada del City Bank con una bomba molotov y erigiendo algunas barricadas. Días después se vivieron eventos similares en las puertas del diario La Capital y el Jockey Club, cuando un grupo conocido por la sigla MAN (Movimiento Anticomunista Nacional) secuestró a Guillermo César Aragón, estudiante de Psicología y militante del FEN. Las movilizaciones duraron dos dias, hasta que fue liberado el joven cautivo.

Para noviembre, según recuerda Luis Díaz Molano: "Me vuelan el estudio de abogado que me había puesto, en la misma noche que incendian la librería Ross, creo que porque había mucho marxismo en venta". ${ }^{14} \mathrm{Se}$ trataba de un ataque a un abogado de reconocido compromiso político, de un perfil similar al de Horacio Zamboni, ex militante estudiantil y representante letrado del SOEPU. Un mes después, en Mar del Plata, la Concentración Nacional Universitaria (CNU) asesinó a Silvia Filler. Se estaban consolidando, a nivel nacional, las prácticas parapoliciales.

En medio de esta lucha antirrepresiva recomenzaba la agitación en Medicina. Algunos estudiantes formaron grupos de ataque, pertrecharon a sus colegas con palos y maderas y organizaron fogatas y barricadas. Por estos hechos fueron detenidos cinco estudiantes. Los alumnos solicitaron al decano que intercediese ante la policía y, cuando el funcionario se negó, se produjo una interpelación violenta. Entonces, las autoridades expulsaron a tres estudiantes, entre ellos Miguel Godoy (presidente del Centro de Estudiantes y del MNR). En respuesta el movimiento estudiantil ocupó nuevamente la Facultad.

Durante la primera semana de octubre se produjeron numerosas movilizaciones y concentraciones en el centro de Rosario, que reclamaron la anulación de las sanciones y la libertad de los presos políticos, entre ellos los estudiantes de Medicina. Varias de estas manifestaciones, protagonizadas por MNR, Franja Morada, UEL y FEN, terminaron en violentas luchas callejeras.

Días después el MNR comenzó una campaña por la expulsión del Decano, quien mantenía cerrada la Facultad y amenazaba finalizar el ciclo lectivo. Los estudiantes de Medicina detenidos recuperaron su li-

14. Entrevista a Luis Díaz Molano, militante de MENAP en la Facultad de Derecho de la UNR, 1966-1971. Realizada por el autor en noviembre de 2009. 
bertad a fin de mes y las bases estudiantiles terminaron 1971 sin rendir exámenes, en cumplimiento de la huelga decretada por el Centro de Estudiantes. Como vemos, durante 1971 la alianza obrero-estudiantil prácticamente no se constituyó en el escenario rosarino.

Institucionalización y represión, el movimiento estudiantil durante 1972

El desarrollo del movimiento estudiantil durante 1972 estuvo signado por dos fenómenos: la continuidad de la actividad represiva y la reorganización de los Centros de Estudiantes. El primero encorsetó la movilización, aunque también constituyó un eje capaz de sortear las divisiones del movimiento. El segundo ubicó al MNR, una fuerza moderada de la izquierda reformista, como la organización más representativa de la ciudad.

Los primeros hechos de importancia durante este año los registramos en abril. A causa del asesinato del teniente general Juan Carlos Sánchez (reivindicado por ERP y FAR como una operación conjunta) la policía detuvo varios estudiantes por una supuesta vinculación con el hecho, motivando agitación entre el alumnado, acicateado también por comunicados intimidantes de la CNU.

En el contexto de una fuerte vigilancia en la ciudad, hacia fin de mes los estudiantes reclamaron la ampliación de los cupos del comedor estudiantil. Pese a protagonizar violentos choques con la policia conquistaron las plazas para nuevos comensales. Semanas después, las manifestaciones en reivindicación de los hechos de mayo de 1969 también concluyeron en serios enfrentamientos con las fuerzas del orden.

Tras estos acontecimientos el movimiento estudiantil rosarino ingresó en un reflujo prolongado, del que emergió a causa de dos fenómenos externos: el Quintazo tucumano, a fines de junio, y el repudio de la masacre de Trelew. Durante los dias 22 y 23 de agosto, como en otras ciudades (Bonavena, 2011), el centro fue escenario de encuentros con piedras, gases lacrimógenos y barricadas que parecían calcados del año 1969. Sin embargo, en 1972 la composición de la masa movilizada era diferente: el movimiento obrero no estaba allí.

En este contexto, durante septiembre los estudiantes de Derecho y Económicas enfrentaron el cierre de sus facultades por "agitación ideológica". Los alumnos se manifestaron por las calles y lograron la reapertura de sus facultades. Luego el movimiento ingresó en un impasse hasta fines de noviembre, cuando todas las corrientes se movilizaron en el centro de la ciudad por la libertad del estudiante Roberto Bravo, quien era sometido a malos tratos en su cautiverio, y, posteriormente, en reclamo por el secuestro y desaparición de "Tacuarita" Brandazza, militante de la JUP. 
Durante la última parte del año comenzaron los debates sobre las elecciones de 1973. FAUDI y TUPAC se manifestaban por el abstencionismo, mientras que el MNR, Franja Morada (desde 1971 convertida en una agrupación estrictamente radical) y el MOR apoyaban distintas variantes electorales. Casi al mismo tiempo, el congreso de FUA Córdobano permitió que se acreditaran los delegados del MOR, agrupación que conducía FUA La Plata. Mientras tanto, en la UNR las elecciones para centros de estudiantes tenían un claro ganador: el MNR. Este colectivo se impuso en Bioquímica, Medicina y Económicas. A nivel de toda la universidad cuadruplicaba a sus perseguidores inmediatos del MOR, victorioso en Ingenieria, y Franja Morada, que habia vencido en Derecho. ${ }^{15}$ Estas distancias siguieron firmes durante 1973, cuando el MNR casi triplicó los votos del MOR. ${ }^{16}$

La lucha contra el continuismo durante la víspera de la "primavera camporista"

Para el movimiento estudiantil rosarino el comienzo de 1973 estuvo signado por el cambio de régimen que se avecinaba. Hacia fines de marzo, incluso con un presidente electo, el rector Brebbia pretendió una "normalización universitaria" bajo los mecanismos previstos en la legislación de 1967. Se constituyeron los Consejos Académicos y fue convocada una Asamblea Universitaria para elegir autoridades. Las agrupaciones peronistas y reformistas rechazaron esta iniciativa, calificándola como una maniobra para aferrarse a los cargos. En igual sentido se expresaron numerosos docentes y la CGT Rosario, que tras un largo silencio retomó su vinculación con las cuestiones universitarias. En sintonía, la Federación Universitaria de Rosario reclamó la nulidad de lo actuado desde 1966, el regreso de la autonomía y la inhabilitación de los funcionarios de la dictadura para desempeñarse en la Universidad bajo el próximo gobierno. Esta lucha común acercó las posiciones de reformistas y peronistas, quienes lograron suspender la Asamblea Universitaria. La derrota del llamado "continuismo" alentó un cuestionamiento más profundo de las estructuras universitarias legadas de la dictadura. En varias facultades se reclamó el alejamiento de los docentes nombrados durante los años previos, algunos sindicados como beneficiarios de concursos fraudulentos.

Al mismo tiempo, hacia mediados de mayo primaba un clima de re-

15. La suma de los guarismos de 1972 seria: MNR, 2.163; MOR, 586, y Franja Morada, 385. Ver: BDB, sección diciembre de 1975, p. 12.

16. "Triunfo radical-socialista en la Universidad Nacional de Rosario", La Opinión, 20 de noviembre de 1973, p. 11. 
gocijo y de notoria pacificación: tanto el reformismo como el peronismo colocaban placas con los nombres de los estudiantes caídos durante los siete años de gobiernos de facto en las aulas de la UNR. En Rosario, pero también a nivel nacional, se estaba fortaleciendo una confluenciadel MOR, Franja Morada y FAUDI con el peronismo nucleado en la Coordinadora Universitaria Peronista (CUP). Sin embargo, aquella convergencia no era un asunto sencillo. Los justicialistas criticaban los centros de estudiantes, forma típica de organización reformista, y proponían la participación del Poder Ejecutivo en el gobierno universitario, contraviniendo la tradicional consigna por la autonomía. La llegada de un nuevo gobierno peronista, desde el 25 de mayo, constituyó un nuevo escenario para la militancia estudiantil.

\section{Conclusiones}

En este artículo reconstruimos la experiencia del movimiento estudiantil rosarino desde el Cordobazo hasta el final de la autodenominada "Revolución Argentina". Reseñamos episodios de su trayectoria previa, como el cincuentenario de la Reforma de 1918 y los hechos de mayo de 1969, que fundamentaron ciertas condiciones para su integración subordinada en la alianza obrero-estudiantil con la cual protagonizó el Rosariazo.

Observamos que posteriormente, el movimiento estudiantil llevó a cabo numerosas luchas académico-corporativas, como las campañas por el ingreso irrestricto en 1970 y 1971, o los enfrentamientos en diversas facultades acerca de planes de estudio, condiciones edilicias, posicionamientos políticos de los docentes, etc. En muchas de estas pujas, el movimiento estudiantil rosarino presentó formas de acción directa y, en reiteradas ocasiones, protagonizó violentos choques con la policía. La herramienta organizativa más estable y eficaz, sin desconocer la emergencia de eventuales Coordinadoras, fueron los Centros de Estudiantes. Las agrupaciones de mayor influencia en estos conflictos y en estas organizaciones fueron aquellas que reivindicaban la tradición reformista, tanto desde un punto de vista democrático burgués, como vaga o más firmemente socialista: Franja Morada, MNR, MOR y FAUDI. La agrupación estudiantil peronista más importante del periodo, el FEN, desde 1970-1971 se encontraba en camino hacia la ortodoxia justicialista, desde la cual mantuvo distancia con la dictadura de Lanusse, pero también con el reformismo y la izquierda estudiantil.

En este sentido, la construcción de la izquierda peronista en la UNR es un proceso que bordea el final de la dictadura y que carece de éxitos tan resonantes como en Buenos Aires, donde conquistó la federación estudiantil durante 1973. Al mismo tiempo, vale recordar que Rosario 
fue una de las primeras regionales de Montoneros donde se produjo la fractura de La Lealtad, a menos de dos meses de que Perón asumiera la presidencia. No corresponde, entonces, hablar de peronización, algo que advertían en 1972 las ex cátedras nacionales: "Nos apoyábamos [...] en nuestra experiencia para hablar de la quiebra de la universidad". ${ }^{17}$

No obstante las diferencias, subrayamos que desde el GAN el movimiento estudiantil rosarino afrontó la represión clandestina y paramilitar. En este punto, la unidad entre los alumnos reformistas, marxistas y peronistas fue sólida.

Finalmente, recalcamos que desde el Rosariazo hasta 1973 se fue desdibujando la alianza obrero-estudiantil. En buena medida por la temprana extinción de la CGT-A en Rosario (mayo de 1969) y el encuadramiento de los principales gremios en la ortodoxia sindical peronista. Además, por la precariedad de las experiencias clasistas locales, como la Intersindical de San Lorenzo, si las comparamos con las organizaciones de Córdoba. Pero también a causa de la trayectoria de los alumnos. Pese al radicalismo de sus formas de acción, el movimiento estudiantil estuvo centrado, desde 1971, en la arena universitaria y su interpelación hacia posibles aliados se enfocó más en los habitantes de la ciudad que en la clase obrera. Conjeturamos que en estas formas de acción se expresaba parte de la orientación del hegemónico MNR rosarino, aliado fundamental de Franja Morada, enrolado en un partido como el PSP, que llamaba a la "conquista de las grandes mayorias nacionales" en detrimento de una política clasista.

\section{Bibliografia}

Balvé, Beba y Beatriz Balvé (2005), El 69. Huelga politica de masas. Rosariazo, Cordobazo, Rosariazo, Buenos Aires: CICSO-Razón y Revolución.

Barletta, Ana María (2001), "Peronización de los universitarios (1966-1973). Elementos para rastrear la constitución de una política universitaria peronista", Pensamiento Universitario, $\mathrm{n}^{\circ}$ 9, Buenos Aires, pp. 82-89.

Bonavena, Pablo (1990-1992), "Las luchas estudiantiles en Argentina 19661976", Informe de Beca de Perfeccionamiento, Secretaria de Ciencia y Técnica, UBA.

Bonavena, Pablo (2011), "El movimiento estudiantil frente a la masacre en Trelew del 22 de agosto de 1972", Conflicto Social, año 4, n 5, Buenos Aires, pp. 201-230.

Bonavena, Pablo et al. (1998), Orígenes y desarrollo de la guerra civil en Argentina (1966-1976), Buenos Aires: Eudeba.

Bonavena, Pablo y Mariano Millán (2007), “¿Cómo llegó el movimiento es-

17. "De base y con Perón", Antropología del Tercer Mundo, junio de 1972, n 10, p. 30-31. 
tudiantil rosarino al Rosariazo de mayo de 1969?”, Razón y Revolución, $\mathrm{n}^{\circ} 17$, Buenos Aires, pp. 117-128.

Bou, Luis César (2002), "El espontaneísmo en los movimientos de masas: El caso de Rosario en 1969", Observatorio de Conflictos, Argentina.

Califa, Juan (2016), “Obreros y estudiantes ¿unidos y adelante? Los estudiantes de la Universidad de Buenos Aires frente al movimiento obrero bajo la "Revolución Argentina", 1966-1973", Archivos, no 8, pp. 141-160.

Califa, Juan y Mariano Millán (2016), "La represión a las universidades y al movimiento estudiantil argentino entre los golpes de Estado de 1966 y 1976", $H I b, \mathrm{n}^{\circ}$ 9, vol. 2, Madrid, pp. 10-38.

Celentano, Adrián (2014), "Universidad y lucha de clases: la formación de las agrupaciones estudiantiles maoístas entre el Cordobazo y el retorno del peronismo al poder", ponencia en las V Jornadas de Estudio y Reflexión sobre el Movimiento Estudiantil Argentino y Latinoamericano, UNMdP.

Ceruti, Leónidas y Mariano Resels (2006), Democracia directa y gestión obrera. El SOEPU, la Intersindical de San Lorenzo y la Coordinadora de Gremios, 1962-1976, Rosario: Del Castillo.

González, Oscar, et al. (2009), Los rosariazos de 1969. De mayo a septiembre, Rosario: Homo Sapiens.

Kautsky, Karl (1975), "Una nueva estrategia", en AA.VV., Debate sobre la huelga de masas, México: Pasado y Presente, pp. 189-228.

Mangiantini, Martín (2014), El trotskismo y el debate en torno a la lucha armada, Buenos Aires: El Topo Blindado.

Millán, Mariano (2013), "Entre la Universidad y la politica. Los movimientos estudiantiles de Corrientes y Resistencia, Rosario, Córdoba y Tucumán durante la "Revolución Argentina" (1966-1973)", tesis de doctorado en Ciencias Sociales, Buenos Aires: FSOC-UBA.

Neirot, Alberto (2010), "Montoneros: génesis de su conformación en Rosario, 1970-1974", en Laura Pascuali y Oscar Videla (comps.), El contenido de los conflictos. Formas de lucha sociopolitica en la historia argentina reciente. 1966-1996, Rosario: La Quinta Pata, pp. 43-66.

O’Donnell, Guillermo (2009), El Estado burocrático autoritario, Buenos Aires: Prometeo.

Pérez, Nestor y María Viano (1994), "El 69: del Mayo rosarino al Rosariazo", en Patricia Berrotarán y Pablo Pozzi (comps.), Estudios inconformistas sobre la clase obrera argentina, 1955-1989, Buenos Aires: Letra Buena, pp. 89-114.

Pérez Lindo, Augusto (1986), Universidad, politica y sociedad, Buenos Aires: Eudeba.

Portantiero, Juan Carlos (1978), Estudiantes y politica en América Latina, México: Siglo XXI.

Pozzi, Pablo y Alejandro Schneider (2000), Izquierda y clase obrera: 19691976, Buenos Aires: Eudeba.

Reta, Marina (2010), "El proceso de peronización dentro del movimiento universitario en los años sesenta en Argentina. El caso del Frente Estu- 
diantil Nacional", tesis de maestría en Investigación en Ciencias Sociales, Buenos Aires: FSOC-UBA.

Ruiz, Guillermo y Savina Vargas (2013), “Juventud y peronización. el caso del Frente Estudiantil Nacional en Rosario en los albores de la década del 70", ponencia presentada en las XIV Jornadas Interescuelas / Departamentos de Historia, Departamento de Historia FFyL, UNCu.

Sarlo, Beatriz (2001), La batalla de las ideas (1943-1973), Buenos Aires: Emecé.

Sigal, Silvia (1991), Intelectuales y poder en la década del sesenta, Buenos Aires: Puntosur.

Sommier, Isabelle (2009), La violencia revolucionaria, Buenos Aires: Nueva Visión.

$$
* * *
$$

Titulo: Rosario's student movement's struggles from the Cordobazo to the "primavera camporista" (1969-1973)

Resumen: En este artículo analizamos las luchas del movimiento estudiantil rosarino desde el Cordobazo hasta el final de la dictadura militar, entre mayo de 1969 y mayo de 1973. Destacamos su participación en el Rosariazo, las luchas por el ingreso irrestricto, los conflictos académico-corporativos y las movilizaciones contra la represión estatal y paraestatal durante el GAN. Prestamos atención a las modalidades de los enfrentamientos (formas de acción y de organización, reclamos), al derrotero de la unidad obrero-estudiantil y a las posiciones políticas dentro del movimiento mostrando que, en contradicción con hipótesis difundidas, el reformismo universitario nucleó actores clave para comprender al movimiento estudiantil de los 70 .

Palabras clave: Movimiento estudiantil - Rosario - Revolución Argentina - Radicalización

Abstract: In this article we analyze the struggles of Rosario's student movement, from the Cordobazo in May of 1969, until the end of the military dictatorship in May of 1973. We highlight the student's participation in the Rosariazo, the struggles against university's admissions exams, academic-corporate conflicts and mobilizations against state and parastatal repression during the GAN. We look to the confrontation's modalities (forms of action and organization, demands), the course of worker-student unity and the political positions within the movement, showing that, in contradiction to widespread hypotheses, university reformism was fundamental in the student movement during the seventies.

Key Words: Student movement - Rosario - Argentinian Revolution - Radicalization

Recepción: 3 de enero de 2017. Aprobación: 4 de marzo de 2017. 